(c) American Dairy Science Association, 2003.

\title{
Nucleotide Sequencing, Purification, and Biochemical Properties of an Arylesterase from Lactobacillus casei LILA
}

\author{
K. M. Fenster, ${ }^{\star}$ K. L. Parkin, ${ }^{*}$ and J. L. Steele ${ }^{\star}$ \\ *Department of Food Science, University of Wisconsin-Madison, \\ Madison 53706
}

\section{ABSTRACT}

An esterase gene, designated est $B$, was isolated from a genomic library of Lactobacillus casei LILA. Nucleotide sequencing of the est $B$ gene revealed a 954-bp open reading frame encoding a putative peptide of $35.7 \mathrm{kDa}$. The deduced amino acid sequence of EstB contained the characteristic GXSXG active-site serine motif identified in most lipases and esterases. An EstB fusion protein containing a C-terminal 6-histidine tag was constructed and purified to electrophoretic homogeneity by affinity chromatography. The native molecular weight of EstB was $216.5 \pm 2.5 \mathrm{kDa}$, while the subunit molecular weight was $36.7 \pm 1.0 \mathrm{kDa}$. Optimum $\mathrm{pH}$, temperature, and $\mathrm{NaCl}$ concentration for EstB were determined to be $\mathrm{pH} 7.0,50$ to $55^{\circ} \mathrm{C}$, and $15 \% \mathrm{NaCl}$, respectively. EstB had significant activity under conditions simulating those of ripening cheese $\left(\mathrm{pH} 5.1,10^{\circ} \mathrm{C}\right.$, and $\left.4 \% \mathrm{NaCl}\right)$. Kinetic constants $\left(\mathrm{K}_{\mathrm{M}}\right.$ and $\mathrm{V}_{\max }$ ) were determined for EstB action on a variety of ethyl esters and ester compounds consisting of substituted phenyl alcohols and short $n$-chain fatty acids. For comparison purposes, EstA from $L b$. helveticus CNRZ32 was purified to electrophoretic homogeneity and its substrate selectivity determined in a similar fashion. Different substrate selectivities were observed for EstB and EstA.

(Key words: Lactobacillus casei, arylesterase, nucleotide sequencing, purification)

\begin{abstract}
Abbreviation key: Ap = ampicillin, $\mathbf{a}_{\mathbf{w}}=$ water activity, DFP = diisopropyl fluorophosphate, IAA = iodoacetic acid, IPTG = isopropyl-thio- $\beta$-D-galactoside, $\mathbf{L A B}=$ lactic acid bacteria, $\mathbf{L B}=$ Luria-Bertani, $\mathbf{M E S}=2-(N$ morpholino) ethanesulfonic acid, $\mathbf{O R F}=$ open reading frame, PCMB $=p$-chloromercuribenzoic acid, PGL = pregastric lingual lipase, PMSF = phenylmethylsulfonyl fluoride, $\boldsymbol{p} \mathbf{N P}=p$-nitrophenyl, $\mathbf{X}$-Gal $=5$-bromo-4chloro-3-indoyl- $\beta$-D-galactoside.
\end{abstract}

Received December 8, 2002.

Accepted January 20, 2003.

Corresponding author: J. L. Steele; e-mail: jlsteele@facstaff. wisc.edu.

\section{INTRODUCTION}

Lipolysis of milk fat in ripening cheese produces fatty acids, which contribute directly to cheese flavor by imparting specific fatty acid flavor notes, or indirectly as precursors for the formation of other flavor compounds (Woo et al., 1984; McSweeney and Sousa, 2000). Short $n$-chain FA, such as butanoate, hexanoate, and octanoate are important for the characteristic flavor development of Italian cheeses, such as Parmesan, Grana Padano, Romano, and Provolone, and constitute the majority of volatile FA released from milk fat by lipases (EC 3.1.1.3) (Woo et al., 1984; Woo and Lindsay, 1984; $\mathrm{Ha}$ and Lindsay, 1993). Short $n$-chain FA, which are liberated from milk triacylglycerols, can become esterified to ethanol to produce highly flavorful ethyl esters in ripening cheese (Ha and Lindsay, 1992; McSweeney and Sousa, 2000). In Parmesan and Grana Padano cheeses, ethyl butanoate and ethyl hexanoate are believed to play an important role in the formation of the characteristic fruity flavors associated with these cheese varieties (Moio and Addeo, 1998; Barbieri et al., 1994; Meinhart and Schreier, 1986; Dumont et al., 1974).

Thermophilic lactic acid bacteria (LAB), such as $L b$. helveticus, Lb. delbrueckii, Lb. fermentum, and Streptococcus thermophilus, are used as starter cultures in the production of Parmesan and Grana Padano cheese (Battistotti and Corradini, 1993; Johnson, 2001). The microflora of cheese immediately after manufacture is dominated by starter LAB, which reach $10^{8}$ to $10^{9} \mathrm{cfu} /$ g cheese (Beresford et al., 2001). Starter LAB levels typically decrease to $10^{4} \mathrm{cfu} / \mathrm{g}$ cheese after 4 to $6 \mathrm{wk}$ with the concomitant increase of nonstarter LAB, such as $L b$. casei, reaching levels of $10^{6}$ to $10^{7} \mathrm{cfu} / \mathrm{g}$ cheese (Beresford et al., 2001). Little is known about the contribution of lipases and esterases (EC 3.1.1.1) from LAB to the formation of cheese flavor in Parmesan and Grana Padano (Gobbetti et al., 1997a; Gobbetti et al., 1997b). However, given the high cell densities reached by starter and nonstarter LAB as well as the long ripening time, lipases and esterases from LAB may play an important role in flavor development of these cheeses (Gobbetti et al., 1996a). It is well established that pre- 
gastric lingual lipases (PGL) from calf, kid, or lamb are required for typical flavor development of some Italian cheeses, such as Romano and Provolone (Battistotti and Corradini, 1993; Gobbetti et al., 1996a; Johnson, 2001). However, in others, such as Parmesan and Grana Padano, where PGL are not used, the typical flavors associated with lipolysis in these cheeses are probably due to indigenous milk lipases, and lipases and esterases from starter and nonstarter LAB (Battistotti and Corradini, 1993; Johnson, 2001).

The lipase and esterase activities of several thermophilic and mesophilic lactobacilli have been described (Gobbetti et al., 1996a). Esterases and lipases of LAB have recently been purified from $L b$. casei (Fenster et al., accepted; Castillo et al., 1999), Lb. plantarum (Gobbetti et al., 1997a; Gobbetti et al., 1996b), Lb. fermentum (Gobbetti et al., 1997b), Lb. helveticus (Fenster et al., 2000), Lactococcus lactis (Tsakalidou and Kalantzopoulos, 1992; Holland and Coolbear, 1996; Chich et al., 1997; Fernández et al., 2000; Fenster et al., accepted), and St. thermophilus (Liu et al., 2001). Characterization of these esterases and lipases has shown that some of these enzymes could play an important role in cheese flavor development. Many of these enzymes could contribute to cheese flavor development by hydrolyzing short $n$-chain fatty acids from milk fat at elevated water activity $\left(\mathbf{a}_{\mathbf{w}}\right)$ and synthesizing esters as $\mathrm{a}_{\mathrm{w}}$ decreases with ripening (Ha and Lindsay, 1992; Liu et al., 1998).

This manuscript describes the biochemical characterization of an arylesterase (EC 3.1.1.2), designated EstB, from $L b$. casei LILA. The substrate selectivity of purified arylesterase, EstA, from $L b$. helveticus CNRZ32 (Fenster et al., 2000) was determined in a similar fashion for comparison. EstB and EstA were also compared to determine if they shared a common molecular mechanism for substrate selectivity. The potential role of these esterases in cheese flavor development is discussed based on their substrate selectivity and sensitivity to environmental conditions encountered in ripening cheese.

\section{MATERIALS AND METHODS}

\section{Bacterial Strains, Media, and Plasmids}

Lb. casei LILA was obtained from the University of Wisconsin Center for Dairy Research Culture Collection. Escherichia coli DH5 $\alpha$ (Gibco-BRL Life Technologies, Inc., Gaithersburg, MD) and TOP 10 E. coli cells (Invitrogen Corporation/Novex, Carlsbad, CA) were grown in Luria-Bertani $(\mathbf{L B})$ broth at $37^{\circ} \mathrm{C}$ with aeration (Sambrook et al., 1989). Lb. casei and Lb. helveticus strains were grown in MRS broth at $37^{\circ} \mathrm{C}$ without shaking (De Man et al., 1960). Agar plates were prepared by adding $1.5 \%$ (wt/vol) granulated agar (Difco Laboratories, Detroit, MI) to liquid media. The concentrations of antibiotics added to liquid media or agar plates for selection of plasmids were as follows: pUC-18 (GibcoBRL), $100 \mu \mathrm{g}$ of ampicillin (Ap)/ml; pMOB (Gold Biotechnology, St. Louis, MO), $100 \mu \mathrm{g}$ of Ap or $100 \mu \mathrm{g}$ of carbenicillin/ml; pQE-12 (Qiagen, Inc., Chatsworth, $\mathrm{CA}), 100 \mu \mathrm{g}$ of Ap/ml; and pREP-4 (Qiagen), $25 \mu \mathrm{g}$ of kanamycin $/ \mathrm{ml}$. All antibiotics were obtained from Sigma Chemical Co. (St. Louis, MO). For experiments utilizing $\alpha$-complementation, isopropyl-thio- $\beta$-galactoside (IPTG) (Gibco-BRL) and 5-bromo-4-chloro-3-indoyl- $\beta$-D-galactoside (X-Gal) (Gibco-BRL) were added to agar media at concentrations of 119 and $40 \mathrm{mg} / \mathrm{L}$, respectively.

\section{Genomic Library Construction}

A late-log phase culture $(100 \mathrm{ml})$ of $L b$. casei LILA was lysed as described by Anderson and McKay (1983) and chromosomal DNA was isolated from this lysate using the method described by Marmur (1961). Plasmid DNA was isolated from $E$. coli using the Quantum Prep Plasmid Miniprep and Plasmid Midiprep Kits (Bio-Rad Laboratories, Richmond, CA).

Chromosomal DNA from $L b$ casei LILA was partially digested with Sau3A and 4.5 to $9.0 \mathrm{kbp}$ fragments were isolated from low-melting agarose gels (Gibco-BRL) using QIAquick Gel Extraction Kit (Qiagen). The vector pUC-18 was digested with BamHI, treated with alkaline phosphatase, and ligated with the $4.5-9.0 \mathrm{kbp}$ Sau3A chromosomal fragments. One Shot TOP 10 chemically competent $E$. coli cells (Invitrogen) were transformed with the ligation products as per the manufacturer's instructions. After expression, the transformants were plated on LB-Ap agar containing IPTG and X-Gal. White colonies were transferred with sterile toothpicks to LB-Ap agar to detect esterase activity. Plasmid DNA from individual randomly picked white colonies (approximately 1\% of white transformants were screened) was digested with $E c o$ RI to determine average insert size and percentage of transformants containing inserts. Agarose gel electrophoresis was performed on horizontal submerged gels with $0.04 M$ Trisacetate and 0.001 $M$ EDTA buffer, pH 8.1.

\section{Screening of $L b$. casei LILA Genomic Library}

Esterase activity was qualitatively determined using a previously described pour plate enzyme assay (Fenster et al., accepted) with $1.0 \mathrm{~m} M \beta$-naphthyl butanoate or $\beta$-naphthyl octanoate (Sigma) as substrates. Lb. casei LILA and E. coli Top 10 (pUC-18) were used as positive and negative controls, respectively. 


\section{Molecular Cloning}

Recombinant DNA techniques were performed essentially as described by Sambrook et al. (1989). T4 DNA ligase, alkaline phosphatase, and restriction endonucleases were used as recommended by the manufacturer (Gibco-BRL). E. coli transformations were performed with a Gene Pulser following the instructions recommended by the manufacturer (Bio-Rad). Tn1000 mutagenesis was performed as recommended by the manufacturer (Gold Biotechnology). Pour plate enzyme assays with Fast Garnet GBC and $\beta$-naphthyl butanoate or $\beta$-naphthyl octanoate were conducted to determine which $\mathrm{Tn} 1000$ insertions lacked esterase activity.

\section{DNA Sequencing and Sequence Analysis}

Nested sets of $\operatorname{Tn} 1000$ insertions were generated in estB with the Tn1000 kit (Gold Biotechnology). DNA template isolation and nucleotide sequencing was performed as previously described (Fenster et al., accepted). DNA sequences were analyzed and assembled using Lasergene 5.0 program of DNASTAR, Inc. (Madison, WI). Protein identity and amino acid sequence motif searches were performed using the BLAST network service (Altschul et al., 1990) and the PROSITE Dictionary of Protein Sites and Patterns (Hofmann et al., 1999), respectively. Protein sequence alignment was performed with the MEGALIGN program of Lasergene 5.0 (DNASTAR) and the program ALIGN (Person et al., 1997) from the Institut de Génétique Humaine.

\section{Purification of EstA and EstB}

The $e s t B$ gene was amplified by PCR with Platinum $P f x$ DNA polymerase (Gibco-BRL) and $5^{\prime}$ and $3^{\prime}$ est $B$ primers, which contained a BamHI restriction site on the $5^{\prime}$ end of each primer. The nucleotide sequences of the $5^{\prime}$ and $3^{\prime}$ primers were $5^{\prime}$ cgggatccGCAGATGATGA CATTTTA3' and 5'cgggatccGAGGTCGTCCTCTTCAT C3', respectively (nucleotides in lower-case letters were added in order to introduce the underlined BamHI sites). The PCR product was digested with Bam HI and cloned into the BamHI site of $\mathrm{pQE}-12$. The ligation mixture was transformed into $E$. coli DH5 $\alpha$ (pREP-4). Plasmids containing successful fusions between the est $B$ structural gene and the (His) $)_{6}$ encoding region of pQE-12 were identified by restriction analysis, enzyme assays, and DNA sequencing of estB. Enzyme assays were conducted after inducing expression of the plasmid-encoded estB gene by growing cells in LB broth containing $2.0 \mathrm{~m} M$ IPTG.

Purification of EstB was performed using the QIAexpressionist Protein Purification System (Qiagen) according to the manufacturer's instructions. The one- step purification method is based on affinity of the (His) $)_{6}$ tag for Ni-nitrilotriacetic acid (Ni-NTA), washing away non(His) ${ }_{6}$ tagged proteins with $50 \mathrm{~m} M$ Na-phosphate (pH 8.0), $300 \mathrm{~m} M \mathrm{NaCl}$, and $20 \mathrm{~m} M$ imidazole, and then eluting the protein with a gradient of histidine from 20 to $500 \mathrm{mM}$. Protein profiles in collected fractions were visualized on vertical $12 \%$ SDS-PAGE gels (Sambrook et al., 1989). Fractions containing EstB(His) $)_{6}$ were pooled and dialyzed against $50 \mathrm{~m} M \mathrm{Na}-$ phosphate (pH 8.0) and $300 \mathrm{mM} \mathrm{NaCl}$ at $4^{\circ} \mathrm{C}$.

EstA was purified as previously described (Fenster et al., 2000) using the QIAexpressionist Protein Purification System (Qiagen). E. coli DH5 $\alpha$ (pSUW905), which was used in the previous purification of EstA, was also used in the purification of EstA for this study.

\section{Substrate Specificity of EstB and EstA}

The substrate selectivities of EstB and EstA were examined with a series of substituted $p$-nitrophenyl $(\boldsymbol{p N P})$, ethyl, and acetic acid ester compounds using a standard assay mixture. The standard assay mixture consisted of $15 \mathrm{mM}$ Na-phosphate $(\mathrm{pH} \mathrm{7.5)}$ ) and $4 \%$ $\mathrm{NaCl}$, which was $\mathrm{pH}$-adjusted at the temperatures used for the enzyme assays. Assays were conducted at $35^{\circ} \mathrm{C}$ for EstB and $30^{\circ} \mathrm{C}$ for EstA. Reaction mixtures $(1 \mathrm{ml}$ total reaction volume) were preequilibrated for $5 \mathrm{~min}$ at $35^{\circ} \mathrm{C}$ (for EstB) and $30^{\circ} \mathrm{C}$ (for EstA) prior to initiation of reactions. Reactions were initiated with purified EstB or EstA at protein concentrations of 0.064 to 3.0 $\mu \mathrm{g}$ protein $/ \mathrm{ml}$. Control reactions containing no enzyme were utilized to measure the spontaneous hydrolysis of each substrate tested and deducted from the experimental enzyme assays containing enzyme. Measured reaction rates were verified to be linear under these conditions. Enzyme assays were performed twice in duplicate and the coefficient of variation was $\leq 5 \%$. Kinetic constants $\left(\mathrm{K}_{\mathrm{M}}\right.$ and $\left.\mathrm{V}_{\max }\right)$ were calculated from the Hyperbola (Hyperbol.fit) program of Sigma Plot 3.0 (Jandel Scientific Software, San Rafael, CA). The specific activities of EstB and EstA were expressed as $\mu \mathrm{mol}$ product $/ \mathrm{min} / \mathrm{mg}$ of protein for each of the three series of substrate described in the following paragraphs.

Purified EstB and EstA were each assayed with varying concentrations $(0.0039-4.0 \mathrm{~m} M)$ of $p \mathrm{NP}$ esters of C2-C16 fatty acids (Table 2). Enzyme assays were run continuously for 5 minutes and initial rates of $p$-nitrophenol release by EstB and EstA were quantified by measuring absorbance at $400 \mathrm{~nm}$. The extinction coefficient $\left(\varepsilon_{\mathrm{m} M}\right)$ of $p$-nitrophenol under these conditions was determined to be $22.5 / \mathrm{cm}$ at $400 \mathrm{~nm}$.

Purified EstB and EstA were also assayed with ethyl esters (Sigma) of C2-C6 fatty acids and C3-C6 alkoxy esters of acetate, phenylacetate, and phenylthioacetate 
over a range of concentrations $(1.0-300 \mathrm{~m} M)$. Enzyme assays were conducted for $10 \mathrm{~min}$ and terminated by boiling for $3 \mathrm{~min}$. Reaction rates were quantified on the basis of release of ethanol or acetate using ethanol or acetate detection kits provided by R-Biopharm, Inc. (Marshall, MI).

\section{Characterization of EstB}

Determination of optimum $\mathrm{pH}$, temperature, and $\mathrm{NaCl}$ concentration for EstB employed the standard assay described above using $p$ NP-butanoate. The extinction coefficient $\left(\varepsilon_{\mathrm{m} M}\right)$ of $p$-nitrophenol was determined experimentally for each change in assay conditions. Absorbances were evaluated at 340 and $400 \mathrm{~nm}$ at $\mathrm{pH}$ values lower and higher than 7.0, respectively (Martin et al., 1959). For the $\mathrm{pH}$ study, $15 \mathrm{mM}$ Naphosphate $(\mathrm{pH} 7.5)$ and $4 \% \mathrm{NaCl}$ was replaced by a composite buffer composed of $20 \mathrm{~m} M$ (each) HEPES, malic acid, boric acid, and MES. This composite buffer was also used to compare EstB activity under conditions simulating those of ripening cheese $\left(\mathrm{pH} 5.1,10^{\circ} \mathrm{C}, 4 \%\right.$ $\mathrm{NaCl}$ ) to optimal conditions ( $\left.\mathrm{pH} 7.0,50^{\circ} \mathrm{C}, 15 \% \mathrm{NaCl}\right)$.

Inhibitor studies employed the standard assay described above with $p$ NP-butanoate as the substrate. The inhibitors (Sigma) tested were EDTA, 1,10-phenanthroline, phenylmethylsulfonyl fluoride (PMSF), diisopropyl fluorophosphate (DFP), Pepstatin A, iodoacetic acid (IAA), and $p$-chloromercuribenzoic acid (PCMB). Inhibitors were incubated with $0.33 \mu \mathrm{g}$ protein $/ \mathrm{ml}$ EstB at a final concentration of $1 \mathrm{~m} M$ for $5 \mathrm{~min}$ prior to initiation of assays.

The native molecular weight (MW) of EstB was estimated by gel filtration as previously described (Fenster et al., 2000).

The isoelectric point of EstB was measured as previously described (Fenster et al., 2000). However, individual isoelectric point standards consisting of $\beta$-lactoglobulin (5.1), bovine carbonic anhydrase II (5.4 and 5.9), and human carbonic anhydrase I (6.6) were also used.

\section{Nucleotide Sequence Accession Number}

The sequence for est $B$ has been submitted to GenBank and assigned the accession number AF494421.

\section{RESULTS}

\section{Genomic Library Construction}

A total of 2700 white colonies of $E$. coli Top10 transformants were screened, of which approximately $95 \%$ were determined to contain insert DNA. The average insert size of the clones was $5.3 \mathrm{kbp}$ (data not shown).
By using the equation of Clarke and Carbon (1976) and assuming the genome size of $L b$. casei LILA to be 2500 $\mathrm{kbp}$ (Ferrero et al., 1996), the number of clones required to achieve a 0.99 probability of obtaining a particular chromosomal sequence was calculated to be 2170 clones.

\section{Detection and Isolation of estB}

One clone, designated Top10(pSUW906), from the Lb. casei LILA genomic library was found to hydrolyze $\beta$-naphthyl butanoate and $\beta$-naphthyl octanoate. The esterase activity encoded by pSUW906 was designated EstB. A restriction map of the 4.5-kbp chromosomal insert of pSUW906 was made (data not shown), and a $2.5-\mathrm{kbp}$ XhoI-BamHI fragment was subcloned in pMOB. E. coli DH5 $\alpha$ containing this construct, designated pSUW907, expressed EstB activity and was further characterized. Inactivation of est $B$ by insertions of Tn1000 within the 2.5 -kbp insert of pSUW907 revealed that estB was approximately $1.0-\mathrm{kbp}$ in length (data not shown).

\section{Sequence Analysis}

Approximately 2.4-kbp of the pSUW907 insert was sequenced and an open reading frame (ORF) of 954$\mathrm{bp}$, designated estB, was identified (Figure 1). The ORF could encode a polypeptide of 318 amino acid residues with a deduced mass of $35.7 \mathrm{kDa}$. The ORF start codon is preceded by a putative ribosome binding site (GGAGG; nucleotides -13 to -9) and putative -10 (ATTAAT; nucleotides -48 to -43 ) and -35 (CTGGCA; nucleotides -75 to -70 ) promoter sequences (Shine and Dalgarno, 1974). An inverted repeat (nucleotides 9871007 and 1012-1032) was observed in the $3^{\prime}$ noncoding region and may function as a rho-independent transcriptional terminator with a $\Delta \mathrm{G}$ of $-12.9 \mathrm{kcal} / \mathrm{mol}$ (Tinoco et al., 1973). No ORFs were identified in the 700bp sequence upstream from estB or the 700-bp downstream from est $B$ on the EstB coding strand. Analysis of the ORF indicated that EstB lacks a classical secretion signal sequence (Izard and Kendall, 1994) at the Nterminus of the protein. The amino acid sequence GDSAG, starting at residue 143, is consistent with the GXSXG motif found in most bacterial serine hydrolases, which includes esterases and lipases (Jaeger et al., 1999).

\section{Comparison of Amino Acid Sequences}

Protein sequence searches using BLAST (Altschul et al., 1990) revealed that EstB had 35\% sequence identity with LipP, a lipase of similar size (308 residues) identi- 


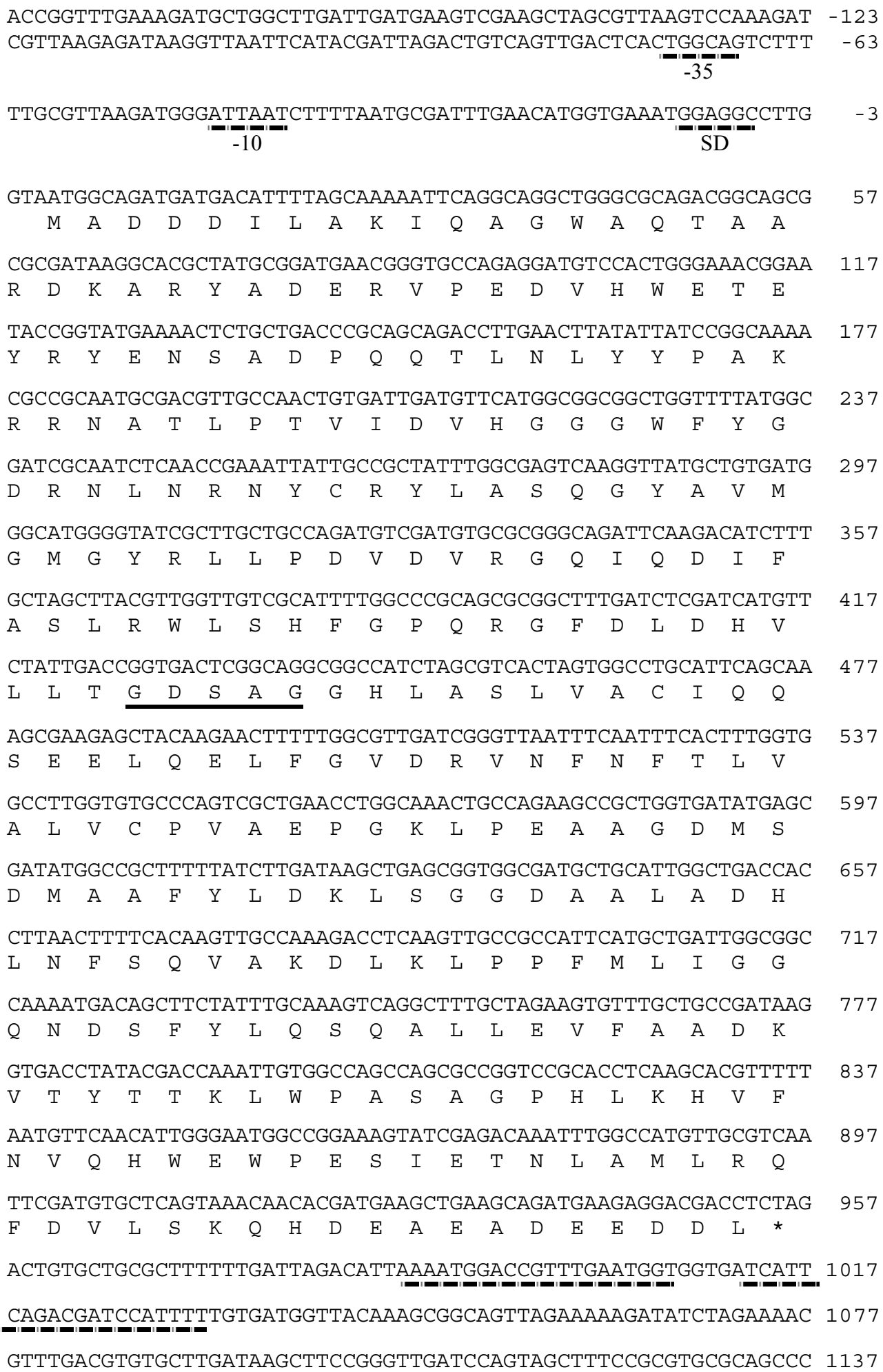

Figure 1. Nucleotide sequence of estB from Lactobacillus casei LILA. The predicted amino acid sequence is given below the nucleotide sequence in single-letter code. The putative -35 and -10 promoter sequences, putative ribosome binding site, and putative transcriptional termination sequence are indicated with dashed lines. An asterisk marks the stop codon. The lipase/esterase active-site serine consensus sequence is underlined with a solid line. 
Panel A

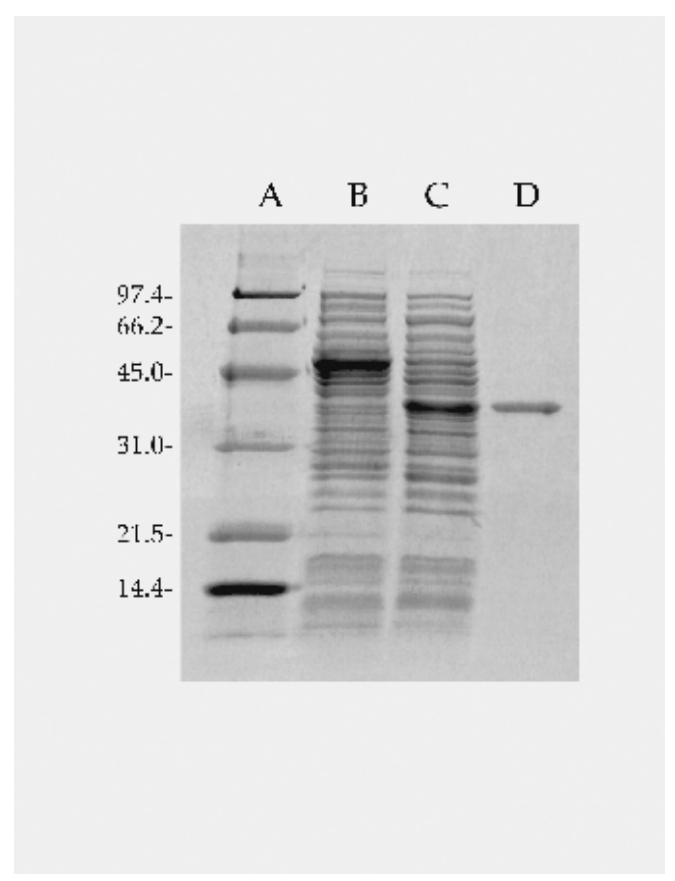

Panel B

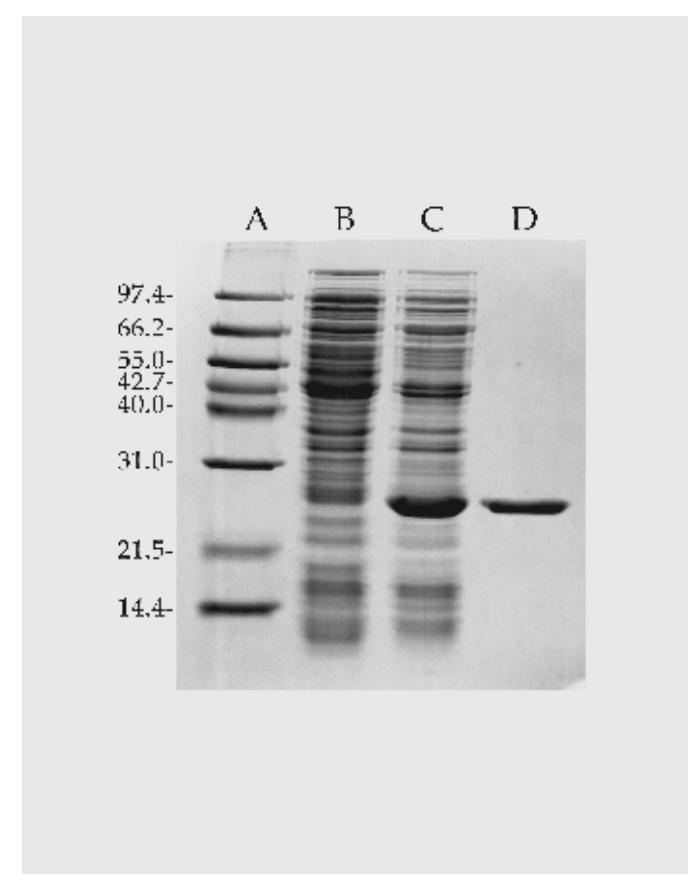

Figure 2. SDS-PAGE gels of purified Lactobacillus casei LILA EstB (Panel A) and Lactobacillus helveticus CNRZ32 EstA (Panel B). Panel A. Lane A: protein standards (phosphorylase B, $97.4 \mathrm{kDa}$; bovine serum albumin, $66.2 \mathrm{kDa}$; ovalbumin, $45.0 \mathrm{kDa}$; carbonic anhydrase, $31.0 \mathrm{kDa}$; soybean trypsin inhibitor, $21.5 \mathrm{kDa}$; lysozyme, $14.4 \mathrm{kDa}$ ); lane B: cell-free extracts (15 $\mu \mathrm{g}$ protein) of DH5 $\alpha$ (pSUW908) grown in the absence of IPTG; lane C: cell-free extracts (15 $\mu \mathrm{g}$ protein) of DH5 $\alpha$ (pSUW908) grown in the presence of $1.5 \mathrm{~m} M$ IPTG; lane D: purified EstB (1.5 $\mu \mathrm{g}$ of protein). Panel B. Lane A: protein standards (phosphorylase B, $97.4 \mathrm{kDa}$; bovine serum albumin, 66.2 kDa; glutamate dehydrogenase, $55.0 \mathrm{kDa}$; ovalbumin, $42.7 \mathrm{kDa}$; aldolase, $40.0 \mathrm{kDa}$; carbonic anhydrase, $31.0 \mathrm{kDa}$; soybean trypsin inhibitor, $21.5 \mathrm{kDa}$; lysozyme, $14.4 \mathrm{kDa})$; lane B: cell-free extracts (20 $\mathrm{g}$ g protein) of DH5 $\alpha$ (pSUW905) grown in the absence of IPTG; lane C: cell-free extracts (20 $\mu \mathrm{g}$ protein) of DH5 $\alpha$ (pSUW905) grown in the presence of $2.0 \mathrm{mM}$ IPTG; lane D: purified EstA (2 $\mu \mathrm{g}$ of protein).

fied from Pseudomonas sp. B11-1 (Choo et al., 1998). The protein sequence searches using BLAST did not find significant homology between the $L b$. casei LILA EstB and $L b$. casei LILA EstC (Fenster et al., accepted) Lb. helveticus CNRZ32 EstA (Fenster et al., 2000) and Lc. lactis MG1363 EstA (Fernandez et al., 2000). EstB was aligned with the LILA EstC, CNRZ32 EstA and MG1363 EstA protein sequences and found to have $19.3,15.5$, and $17.9 \%$ identity with these esterases, respectively.

\section{Purification of EstB and EstA}

Cloning of estB into pQE-12 resulted in a plasmid, designated pSUW908. The orientation of the insert was confirmed by restriction analysis. Nucleotide sequence analysis of pSUW908 confirmed that estB was cloned in frame with the downstream (His) ${ }_{6}$-encoding region of pQE-12 and no mutations had occurred in the nucleotide sequence during routine propagation in $E$. coli.
After induction of EstB expression in DH5 $\alpha$ (pSUW908) with IPTG, the overexpression and enzyme activity of EstB in cell free extracts were evaluated by SDS-PAGE analysis and enzyme assays with $p$ NP-butanoate. EstB was subsequently purified to electrophoretic homogeneity by affinity chromatography (Figure 2).

The cloning of estA into $\mathrm{pQE}-12$, orientation of insert, and DNA sequence analysis of the estA::pQE-12 junctions were previously conducted for pSUW905 (Fenster et al., 2000). In this study, nucleotide sequencing of pSUW905 confirmed these results and verified that no mutations had occurred in the DNA sequence during routine growth of $E$. coli. Induction of EstA expression and subsequent purification of the enzyme was performed as previously described (Fenster et al., 2000) (Figure 2).

\section{Characterization of EstB}

The monomeric MW of EstB was estimated to be 36.7 $\pm 1.0 \mathrm{kDa}$ under protein denaturing conditions (SDS- 
Table 1. The effect of $\mathrm{NaCl}$ concentration on activity of Lactobacillus casei LILA EstB.

\begin{tabular}{ll}
\hline $\mathrm{NaCl}^{1}$ & Specific activity $^{2}$ \\
\hline 0 & $11.7 \pm 0.08$ \\
1 & $12.4 \pm 0.19$ \\
2 & $14.0 \pm 0.57$ \\
3 & $15.1 \pm 0.03$ \\
4 & $16.7 \pm 0.33$ \\
5 & $16.2 \pm 0.35$ \\
7.5 & $18.7 \pm 0.03$ \\
10 & $20.0 \pm 0.24$ \\
12.5 & $19.5 \pm 0.16$ \\
15 & $21.6 \pm 1.0$ \\
17.5 & $19.2 \pm 0.27$ \\
20 & $18.4 \pm 0.27$ \\
\hline${ }^{1} \mathrm{wt} / \mathrm{vol}$. & \\
${ }^{2} \mu \mathrm{mol} / \mathrm{mg} / \mathrm{min}$. &
\end{tabular}

PAGE) (Figure 2). The native MW of EstB was estimated to be $216.5 \pm 2.5 \mathrm{kDa}$ (gel filtration), which suggests that this is a homohexameric enzyme under nondenaturing conditions. Isoelectric focusing of EstB resulted in a single protein band corresponding to a $\mathrm{pI}$ value of $6.1 \pm 0.1$.

The optimum temperature for EstB was between 50 and $55^{\circ} \mathrm{C}$ with a specific activity between $21.7 \pm 0.9$ and $18.7 \pm 0.7 \mu \mathrm{mol} p$-nitrophenol $/ \mathrm{min} / \mathrm{mg}$ of protein. The activation energy $\left(\mathbf{E}_{\mathrm{a}}\right)$ of EstB over the range of 0 to $50^{\circ} \mathrm{C}$ was calculated using an Arrhenius plot to be 8.8 $\mathrm{kcal} / \mathrm{mol}$ (data not shown). Similarly, the $\mathrm{E}_{\mathrm{a}}$ for deactivation of EstB over the range 50 to $60^{\circ} \mathrm{C}$ was determined to be $81.3 \mathrm{kcal} / \mathrm{mol}$.

The optimum $\mathrm{NaCl}$ condition for EstB at $35^{\circ} \mathrm{C}$ was $15 \%$, which corresponded to a specific activity of 21.6 $\pm 1.0 \mu \mathrm{mol} p$-nitrophenol $/ \mathrm{min} / \mathrm{mg}$ of protein (Table 1 ).

The $\mathrm{pH}$ dependence of EstB, presented as a DixonWebb plot (Figure 3), revealed an optimum $\mathrm{pH}$ of 7.0. Since EstB was quite stable between pH 5.0 and 9.5, the observed loss of enzyme activity in the acidic and alkaline ranges was primarily dependent upon proton activation and deactivation of prototropic groups in this $\mathrm{pH}$ range. The major $\mathrm{pH}$ transition for EstB in the alkaline range was conferred by a single prototropic group with an estimated $\mathrm{pK}_{\mathrm{a}}$ range of 9.2 to 9.4 , which suggests that a Cys, Lys, or Tyr residue may be important for activity in this range. The major $\mathrm{pH}$ transition for EstB in the acidic range was conferred by a single prototropic group with an estimated $\mathrm{pK}_{\mathrm{a}}$ range of 5.4 to 5.6, which suggests that an Asp/Glu or His residue may be responsible for controlling activity in this $\mathrm{pH}$ range. A minor $\mathrm{pH}$ transition was observed for EstB at $\mathrm{pH}$ values of 6.0-7.0. Since the effect of change in $\mathrm{pH}$ in this range had a limited impact on enzyme activity, it was not feasible to attribute this minor transition to any specific $\mathrm{pK}_{\mathrm{a}}$ or number of ionizable groups of EstB.

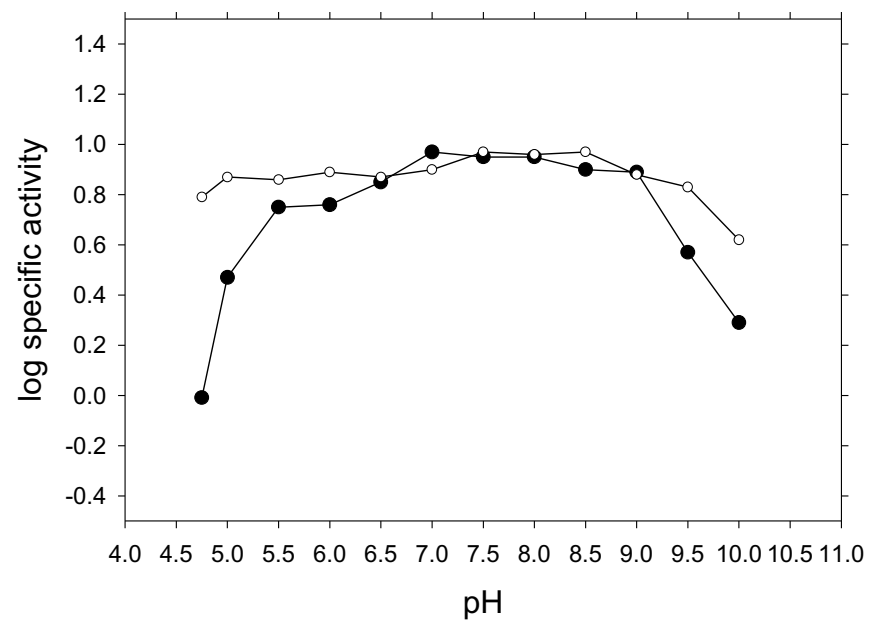

Figure 3. Effect of $\mathrm{pH}$ activity on purified EstB from Lactobacillus casei LILA. Effect of $\mathrm{pH}$ on EstB activity is represented by the close symbol plot (-). Effect of $\mathrm{pH}$ on general enzyme stability of EstB is indicated by the open symbol plot $(\bigcirc)$, which represents specific activity remaining after preincubating at respective $\mathrm{pH}$ values for $5 \mathrm{~min}$ and then assaying with $p$-nitrophenyl butanoate at $\mathrm{pH} 7.5$.

As activities of most eucaryotic and prokaryotic esterases and lipases are dependent upon an active-site triad consisting of Ser-Asp/Glu-His residues, inhibitor studies were conducted to determine if EstB was characteristic of serine-dependent esterases. Of the inhibitors analyzed, PMSF, DFP, and PCMB were found to be the most effective at inhibiting EstB activity (all >99\%) implying that His, Ser and Cys residues, respectively, are essential for activity. However, EstB activity was only slightly inhibited by IAA (6\%), which is also a Cys-targeting inhibitor. Inhibition of EstB activity by Pepstatin A (61\%) suggests that an Asp/Glu residue is also important for activity of EstB.

\section{Substrate Specificity of EstB and EstA}

The substrate specificity of purified EstB and EstA for different fatty acid esters was determined using $p$ nitrophenyl and ethyl esters of C2-C16 and C2 to C6 fatty acids, respectively (Table 2). EstB selectivity for $p \mathrm{NP}$ esters was greatest for $p \mathrm{NP}-\mathrm{C} 5$ and $p \mathrm{NP}-\mathrm{C} 6$, whereas EstA selectivity was greatest for $p$ NP-C2, $p \mathrm{NP}-\mathrm{C} 3$, and $p$ NP-C4. EstB and EstA were not active on $p \mathrm{NP}$ ester substrates with $n$-acyl chain lengths longer than C10 and C8, respectively. EstB selectivity for ethyl esters was observed to be greatest for ethyl hexanoate, whereas EstA selectivity was greatest for ethyl acetate, ethyl propionate, and ethyl butanoate. EstB and EstA were not active on ethyl esters with acyl chain lengths less than C6 and greater than C4, respectively, for the substrate series tested. 
Table 2. Hydrolysis of various esters by purified Lactobacillus casei LILA EstB and Lactobacillus helveticus CNRZ32 EstA.

\begin{tabular}{|c|c|c|c|c|c|c|}
\hline \multirow[b]{2}{*}{ Substrate } & \multicolumn{3}{|c|}{ EstB } & \multicolumn{3}{|c|}{ EstA } \\
\hline & $\mathrm{K}_{\mathrm{M}}^{1}$ & $\mathrm{~V}_{\max }^{2}$ & $\mathrm{~V}_{\max } / \mathrm{K}_{\mathrm{M}}$ & $\mathrm{K}_{\mathrm{M}}$ & $\mathrm{V}_{\max }$ & $\mathrm{V}_{\max } / \mathrm{K}_{\mathrm{M}}$ \\
\hline \multicolumn{7}{|l|}{$p$-Nitrophenyl esters } \\
\hline$p$ NP-acetate ${ }^{3}$ & 1.9 & 20 & 11 & 0.16 & 120 & 750 \\
\hline$p$ NP-propionate & 1.4 & 20 & 14 & 0.063 & 72 & 1100 \\
\hline$p$ NP-butanoate & 0.38 & 17 & 45 & 0.17 & 150 & 880 \\
\hline$p$ NP-pentanoate & 0.063 & 14 & 220 & 0.15 & 7.6 & 52 \\
\hline$p$ NP-hexanoate & 0.029 & 16 & 550 & 0.065 & 3.4 & 51 \\
\hline$p$ NP-octanoate & 0.23 & 8.4 & 37 & 0.12 & 6.5 & 55 \\
\hline$p$ NP-decanoate & 0.084 & 3.2 & 38 & BQL & BQL & BQL \\
\hline$p$ NP-C10 to C16 & $\mathrm{BQL}^{4}$ & $\mathrm{BQL}$ & BQL & $\mathrm{BQL}$ & $\mathrm{BQL}$ & $\mathrm{BQL}$ \\
\hline \multicolumn{7}{|l|}{ Ethyl esters } \\
\hline Ethyl acetate & BQL & BQL & $\mathrm{BQL}$ & 200 & 14 & 0.070 \\
\hline Ethyl propionate & $\mathrm{BQL}$ & BQL & BQL & 95 & 16 & 0.17 \\
\hline Ethyl butanoate & BQL & BQL & $\mathrm{BQL}$ & 59 & 5.4 & 0.092 \\
\hline Ethyl pentanoate & BQL & BQL & BQL & BQL & BQL & BQL \\
\hline Ethyl hexanoate & 3.2 & 4.3 & 1.3 & BQL & BQL & BQL \\
\hline \multicolumn{7}{|l|}{ Acetic acid esters } \\
\hline Propyl acetate & BQL & BQL & BQL & 82 & 4.8 & 0.059 \\
\hline Butyl acetate & BQL & BQL & BQL & 24 & 2.2 & 0.092 \\
\hline Hexanoyl acetate & BQL & BQL & BQL & 2.7 & 0.70 & 0.26 \\
\hline Phenyl acetate & 16 & 640 & 40 & 6.6 & 320 & 48 \\
\hline Phenylthioacetate & 5.5 & 180 & 33 & 7.8 & 320 & 41 \\
\hline \multicolumn{7}{|l|}{${ }^{1} \mathrm{~m} M$} \\
\hline \multicolumn{7}{|l|}{${ }^{2} \mu \mathrm{mol} / \mathrm{mg} / \mathrm{min}$} \\
\hline \multicolumn{7}{|c|}{${ }^{3} p \mathrm{NP}=p$-Nitrophenyl. } \\
\hline
\end{tabular}

The specificity of EstB and EstA toward alcohol functional groups was determined using acetate esters of a series of aromatic and short-chain alcohols (Table 2). Both EstB and EstA preferentially hydrolyzed the aromatic ester substrates, phenyl acetate and phenylthioacetate. EstA also hydrolyzed aliphatic alcohol derivatives of propyl acetate, butyl acetate, and hexyl acetate, whereas activity of EstB on these substrates was below quantifiable limits.

The hyperbolic plots generated from the kinetic data to predict $\mathrm{K}_{\mathrm{M}}$ and $\mathrm{V}_{\max }$ values using the Hyperbola (Hyperbol.fit) program of Sigma Plot 3.0 yielded reasonable fits $\left(r^{2} \geq 0.99\right)$ to the experimental data for EstB and EstA.

\section{DISCUSSION}

This study focused on the molecular characterization of an arylesterase identified from a genomic library of $L b$. casei LILA, and its comparison to a previously identified arylesterase (EstA) from Lb. helveticus CNRZ32 (Fenster et al., 2000). Nucleotide sequencing of this esterase gene, designated estB, revealed a 954bp ORF, which could encode a protein of $35.7 \mathrm{kDa}$. This is differentiated from the ORFs determined for the $L b$. casei LILA estC (Fenster et al., accepted), Lb. helveticus CNRZ32 estA (Fenster et al., 2000), and Lc. lactis
MG1363 estA (Fernandez et al., 2000), which were 777bp, 558-bp, and 774-bp, and could encode putative peptides of $28.9,21.3$, and $29.6 \mathrm{kDa}$, respectively. The presence of putative transcriptional promoter and terminator sequences as well as lack of ORFs immediately upstream/downstream from est $B$, suggests that est $B$ is transcribed monocistronically. This observation was similar to those made for LILA estC (Fenster et al., accepted) and CNRZ32 estA (Fenster et al., 2000), which suggested that these esterases were also transcribed monocistronically.

Protein sequence alignment of EstB and LILA EstC (Fenster et al., accepted), CNRZ32 EstA (Fenster et al., 2000) and MG1363 EstA (Fernandez et al., 2000) revealed $19.3,15.5$, and $17.9 \%$ sequence identity with these enzymes. The low protein sequence identity observed between these esterases suggests that these enzymes are distantly related to one another and are likely to account for differences in esterase activity between these LAB.

The deduced amino acid sequence of EstB lacked a Nterminal secretion signal sequence (Izard and Kendall, 1994) suggesting that this enzyme is located intracellularly. This observation is similar to those made for the deduced amino acid sequences of LILA EstC (Fenster et al., accepted), CNRZ32 EstA (Fenster et al., 2000), and MG1363 EstA (Fernandez et al., 2000), which were 
also determined to lack classical N-terminal signal peptides. With the exception of the purified esterase from Lb. fermentum (Gobbetti et al., 1997b), all of the purified esterases and lipases from $L b$. casei (Castillo et al., 1999), Lb. plantarum (Gobbetti et al., 1997a; Gobbetti et al., 1996b), and St. thermophilus (Liu et al., 2001), were also reported to be located intracellularly. These observations suggest that cell lysis may be important for release and subsequent flavor formation by these enzymes during cheese ripening.

The activity of esterases and lipases is dependent upon a catalytic triad consisting of active-site Ser, Asp/ Glu, and His residues (Jaeger et al., 1999). The activesite serine residue of lipases and esterases is usually conserved in a GXSXG motif in which $\mathrm{X}$ is a variable amino acid residue (Jaeger et al., 1999). The putative active-site serine of EstB is believed to reside in the deduced amino acid sequence GDSAG. The putative catalytic Asp/Glu and His residues of EstB were not identified, since the surrounding sequences for these residues are typically not highly conserved in esterases and lipases.

The dependence of EstB activity on a charge relay system involving an active-site Ser-Asp/Glu-His catalytic triad was suggested by $61 \%$ loss of EstB activity with the Asp/Glu-targeting inhibitor, Pepstatin A, and $>99 \%$ loss of EstB activity with the Ser and His-targeting inhibitors, DFP and PMSF, respectively. Among characterized $L b$. casei esterases, EstB sensitivity to PMSF and DFP was different from that observed for LILA EstC (Fenster et al., accepted), which was not inhibited by DFP and had 27\% loss of activity with PMSF. However, EstB sensitivity to PMSF was similar to that of the IFPL731 esterase (Castillo et al., 1999), which was inactivated by this inhibitor.

Inhibition of EstB activity with the Cys-targeting inhibitors, PCMB (>99\%) and IAA (6\%), suggests that an accessible cysteine residue is important for EstB activity. EstB contains three Cys residues (Cys88, Cys156, and Cys183), which could be accessible for reaction with PCMB and IAA. Given the bulkiness of the benzoate group of $\mathrm{PCMB}$ relative to the acetate group of IAA, reaction of PCMB with an accessible Cys residue is likely to perturb the native conformation of EstB.

Greater selectivity of EstB and EstA for $p$ NP esters of C5-C6 and C2-C4 fatty acids, respectively, suggest that the hydrophobic binding pocket of EstB is able to accommodate longer $n$-acyl chain lengths than EstA. For EstA, increases in fatty acid chain length from C2C8 had minimal effect on $\mathrm{K}_{\mathrm{M}}$; however, it resulted in a pronounced decrease in corresponding reaction velocities. For EstB, increases in fatty acid chain lengths from $\mathrm{C} 2-\mathrm{C} 6$ resulted in decreases in $\mathrm{K}_{\mathrm{M}}$; however, it had little effect on corresponding reaction velocities.
These observations suggest that changes in catalytic efficiency of EstB and EstA within this substrate series were influenced by changes in binding and transitionstate stages, respectively, along the reaction coordinate. Taken together, these enzyme specific differences suggest that EstB would be more likely to modulate longer fatty acid chain (C5-C6) ester profiles in cheese than EstA. However, EstA would be more likely to influence shorter fatty acid chain (C2-C4) ester profiles in cheese than EstB.

Comparison of EstB and EstA substrate selectivities towards ester substrates with $n$-acyl alcohol functional groups of C2-C6 suggests that the binding pocket of EstA can accommodate longer chain length alcohol functional groups than EstB. Greater selectivity of both EstB and EstA towards ester substrates with aromatic rather than $n$-acyl alcohol functional groups prompts the classification of both of these enzymes as arylesterases.

Under conditions simulating cheese ripening ( $\mathrm{pH}$ 5.1, $10^{\circ} \mathrm{C}, 4 \% \mathrm{NaCl}$ ), EstB and EstA exhibited $9.2 \%$ and $4.0 \%$ activity, respectively, relative to that observed under optimal conditions for these enzymes. This residual level of EstB and EstA activity suggests that both of these enzymes could play a role in modulating ester profiles during cheese ripening. Esterases and lipases can mediate both the synthesis and hydrolysis of esters with the equilibrium being dependent upon $\mathrm{a}_{\mathrm{w}}$ and cosubstrate levels (Ha and Lindsay, 1992; Law and Mulholland, 1995; Jaeger et al., 1999). During the lengthy ripening period associated with Italian-type cheeses, selective decreases in free butanoic and hexanoic acids have been reported with concurrent formation of ethyl butanoate and ethyl hexanoate (Woo and Lindsay, 1984; Ha and Lindsay, 1992). These esters, which are potent flavor compounds at less than $5 \mathrm{ppm}$, are important for development of the characteristic "fruity" flavor notes in Italian-type cheeses, such as Parmesan and Grana Padano, as well as "fruity" off-flavors in Cheddar cheese (Bills et al., 1965; Barbieri et al., 1994; Moio and Addeo, 1998; Liu et al., 1998). Ha and Lindsay (1992) reported that a cheese base with $a_{w}$ of 0.75 to 0.90 had significantly lower free butanoic and hexanoic acid and higher ethyl butanoate and ethyl hexanoate in the presence of ethanol than a cheese base with an $\mathrm{a}_{\mathrm{w}}$ of 0.97. Based on these results, $\mathrm{Ha}$ and Lindsay (1992) postulated that the decrease in $\mathrm{a}_{\mathrm{w}}$ associated with aging as well as the formation of ethanol by the ripening microflora favored the synthesis of these ethyl esters in Italian-type cheeses by esterases and lipases. Though the evidence provided by $\mathrm{Ha}$ and Lindsay (1992) is indirect, it suggests that at the beginning of ripening, hydrolysis of esters by esterases and lipases is favored by elevated $\mathrm{a}_{\mathrm{w}}$. However, as ripening proceeds, 
synthesis of esters by these enzymes is favored by decreasing $\mathrm{a}_{\mathrm{w}}$ and the presence of ethanol. Given the selectivity of EstB and EstA for short $n$-chain fatty acids and esters, EstB and EstA could play a role in cheese flavor development.

The selective hydrolysis of phenyl acetate and related ester compounds consisting of substituted phenyl alcohols suggests that EstB is an arylesterase. This property differentiated EstB from the esterases and lipases purified and characterized from $L b$. casei (Castillo et al., 1999; Fenster et al., accepted), Lb. plantarum (Gobbetti et al., 1996b; 1997a), Lb. fermentum (Gobbetti et al., 1997b), Lc. lactis (Tsakalidou and Kalantzopoulos, 1992; Holland and Coolbear, 1996; Chich et al., 1997; Fernández et al., 2000), and St. thermophilus (Liu et al., 2001). EstB was further distinguished from the $L b$. casei IFPL731 esterase characterized by Castillo et al. (1999) by differences in native MW, substrate selectivity, and optimal $\mathrm{pH}$ and temperature conditions. Under nondenaturing conditions, EstB was determined to be a homohexameric enzyme of $216.5 \mathrm{kDa}$ as compared to the IFPL731 esterase, which was determined to be a homotrimer of $105 \mathrm{kDa}$. The substrate binding pocket of EstB could accommodate FA chain lengths of C2$\mathrm{C} 10$, whereas the substrate binding pocket of the IFPL731 esterase could accommodate FA chain lengths of C4-C14. The IFPL731 esterase had optimum temperature and $\mathrm{pH}$ of approximately 25 to $30^{\circ} \mathrm{C}$ and $\mathrm{pH} 7.5$ to 8.0, whereas EstB had optimum temperature and $\mathrm{pH}$ of 50 to $55^{\circ} \mathrm{C}$ and $\mathrm{pH} 6.5$ to 7.0.

Though EstB and EstA were similar in their ability to hydrolyze arylesterase substrates, significant differences were observed in the kinetic mechanisms employed by these enzymes in substrate hydrolysis. These differences suggest that the arylesterase activities observed for these enzymes were not due to a shared kinetic mechanism, but rather due to the ability of the alcohol binding pockets of these enzymes to accommodate large planar structures.

\section{CONCLUSIONS}

EstB and EstA were observed to have significant activity under conditions simulating ripening cheese $\mathrm{pH}$ $\left.5.1,10^{\circ} \mathrm{C}, 4 \% \mathrm{NaCl}\right)$. The selectivity of EstB and EstA for short $n$-chain FA esters suggests that these enzymes could play an important role in cheese flavor development by modulating ester profiles in cheese. Since EstB and EstA were selective for hydrolyzing ethyl hexanoate and ethyl butanoate at elevated $\mathrm{a}_{\mathrm{w}}$, it is possible that these enzymes could synthesize these ethyl esters as $\mathrm{a}_{\mathrm{w}}$ decreases during ripening of lower moisture cheeses, such as Parmesan and Grana Padano. Given the differences in kinetic mechanisms observed for these enzymes, it is likely that EstB and EstA will influence ester profiles in cheese in an enzyme specific manner. To determine the role of EstB and EstA in cheese flavor development, isogenic strains differing in these activities will be constructed and evaluated in cheese trials.

\section{ACKNOWLEDGMENTS}

This project was funded by Dairy Management, Inc. through the Wisconsin Center for Dairy Research and the College of Agricultural and Life Sciences at the University of Wisconsin-Madison.

\section{REFERENCES}

Altschul, S. F., W. Gish, W. Miller, E. W. Myers, and D. J. Lipman. 1990. Basic local alignment search tool. J. Mol. Biol. 215:403-410.

Anderson, D. G., and L. L. McKay. 1983. Simple and rapid method for isolating large plasmid DNA from lactic streptococci. Appl. Environ. Microbiol. 46:549-552.

Barbieri, G., L. Bolzoni, M. Careri, A. Mangia, G. Parolari, S. Spagnoli, and R. Virgili. 1994. Study of the volatile fraction of Parmesan cheese. J. Agric. Food Chem. 42:1170-1176.

Battistotti, B., and C. Corradini. 1993. Italian cheese. Pages 221244 in Cheese: Chemistry, Physics, and Microbiology, Vol. 2. P. F. Fox, ed. Chapman \& Hall, London, United Kingdom.

Beresford, T. P., N. A. Fitzsimons, N. L. Brennan, and T. M. Cogan. 2001. Recent advances in cheese microbiology. Int. Dairy J. $11: 259-274$.

Bills, D. D., M. E. Morgan, L. M. Libbey, and E. A. Day. 1965. Identification of compounds responsible for fruity flavor defect of experimental Cheddar cheeses. J. Dairy Sci. 48:1168-1173.

Castillo, I., T. Requena, P. Fernandez de Palencia, J. Fontecha, and M. Gobbetti. 1999. Isolation and characterization of an intracellular esterase from Lactobacillus casei subsp. casei IFPL731. J. Appl. Microbiol. 86:653-659.

Chich, J.-F., K. Marchesseau, and J.-C. Gripon. 1997. Intracellular esterase from Lactococcus lactis subsp. lactis NCDO 763: Purification and characterization. Int. Dairy J. 7:169-174.

Choo, D.-W., T. Kurihara, T. Suzuki, K. Soda, and N. Esaki. 1998. A cold-adapted lipase of an Alaskan Pseudomonas sp. strain B111: Gene cloning and enzyme purification and characterization. Appl. Environ. Microbiol. 64:486-491.

Clarke, L., and J. Carbon. 1976. A colony bank containing synthetic E1 hybrid plasmids representative of the entire $E$. coli genome. Cell 9:91-99.

De Man, J. C., M. Rogosa, and M. E. Sharpe. 1960. A medium for the cultivation of lactobacilli. J. Appl. Bacteriol. 23:130-135.

Dumont, J. P., S. Roger, and J. Adda. 1974. Composés volatils du fromage entier et du fromage râpé: Exemple du Parmesan. Lait 54:386-396.

Fenster, K. M., K. L. Parkin, and J. L. Steele. 2000. Characterization of an arylesterase from Lactobacillus helveticus CNRZ32. J. Appl. Microbiol. 88:572-583.

Fenster, K.M., K. L. Parkin, and J. L. Steele. Intracellular esterase from Lactobacillus casei LILA: Nucleotide sequencing, purification, and characterization. J. Dairy Sci. (accepted).

Fernandez, L., M. M. Beerthuyzen, J. Brown, R. J. Siezen, T. Coolbear, R. Holland, and O. P. Kuipers. 2000. Cloning, characterization, controlled overexpression, and inactivation of the major tributyrin esterase gene of Lactococcus lactis. Appl. Environ. Microbiol. 66:1360-1368.

Ferrero, M., C. Cesens, L. Morelli, G. Scolari, and M. Vescovo. 1996. Molecular characterization of Lactobacillus casei strains. FEMS Microbiol. Lett. 140:215-219. 
Gobbetti, M., P. F. Fox, and L. Stepaniak. 1996a. Esterolytic and lipolytic activities of mesophilic and thermophilic lactobacilli. Italian J. Food Sci. 2:127-135.

Gobbetti, M., P. F. Fox, E. Smacchi, L. Stepaniak, and P. Damiani. 1996b. Purification and characterization of a lipase from Lactobacillus plantarum 2739. J. Food Biochem. 20:227-246.

Gobbetti, M., P. F. Fox, and L. Stepaniak. 1997a. Isolation and characterization of a tributyrin esterase from Lactobacillus plantarum 2739. J. Dairy Sci. 80:3099-3106.

Gobbetti, M., E. Smacchi, and A. Corsetti. 1997b. Purification and characterization of a cell surface-associated esterase from Lactobacillus fermentum DT41. Int. Dairy J. 7:13-21.

Ha, J. K., and R. C. Lindsay. 1992. Influence of $a_{w}$ on volatile free fatty acids during storage of cheese bases lipolyzed by kid goat pregastric lipase. Int. Dairy J. 2:179-195.

Ha, J. K., and R. C. Lindsay. 1993. Release of volatile branched-chain and other fatty acids from ruminant milk fats by various lipases. J. Dairy Sci. 76:677-690.

Holland, R., and T. Coolbear. 1996. Purification of tributyrin esterase from Lactococcus lactis subsp. cremoris E8. J. Dairy Res. 63:131-140.

Hofmann, K., P. Bucher, L. Falquet, and A. Bairoch. 1999. The PROSITE database, its status in 1999. Nucleic Acids Res. 27:215-219.

Izard, J. W., and D. A. Kendall. 1994. Signal peptides: Exquisitely designed transport promoters. Mol. Microbiol. 13:765-773.

Jaeger, K.-E., B. W. Dijkstra, and M. T. Reetz. 1999. Bacterial biocatalysts: Molecular biology, three-dimensional structures, and biotechnological applications of lipases. Ann. Rev. Microbiol. $53: 315-351$

Johnson, M. E. 2001. Cheese products. Pages 345-384 in Applied Dairy Microbiology. E. H. Marth and J. L. Steele, ed. Marcel Dekker, Inc., New York, NY.

Law, B. A., and F. Mulholland. 1995. Enzymology of lactococci in relation to flavour development from milk proteins. Int. Dairy J. 5:833-854.

Liu, S.-Q., R. Holland, and V. L. Crow. 1998. Ethyl butanoate formation by dairy lactic acid bacteria. Int. Dairy J. 8:651-657.
Liu, S.-Q., R. Holland, V. L. Crow. 2001. Purification and properties of intracellular esterases from Streptococcus thermophilus. Int. Dairy J. 11:27-35.

Marmur, J. 1961. A procedure for the isolation of deoxyribonucleic acid from microorganisms. J. Mol. Biol. 3:208-218.

Martin, C. J., J. Golubow, and A. E. Axelrod. 1959. A rapid and sensitive spectrophotometric method for the assay of chymotrypsin. J. Biol. Chem. 234:294-298.

McSweeney, P. L. H., and M. J. Sousa. 2000. Biochemical pathways for the production of flavour compounds in cheeses during ripening: A review. Lait 80:293-324.

Meinhart, E., and P. Schreier. 1986. Study of flavour compounds from Parmigiano Reggiano cheese. Milchwissenschaft 41:689-691.

Moio, L., and F. Addeo. 1998. Grana Padano cheese aroma. J. Dairy Res. 65:317-333.

Person, W. R., T. Wood, Z. Zhang, and W. Miller. 1997. Comparison of DNA sequences with protein sequences. Genomics 46:24-36.

Sambrook, J., E. F. Fritsch, and T. Maniatis. 1989. Molecular Cloning: A Laboratory Manual, 2nd ed. Cold Spring Harbor Laboratory, Cold Spring Harbor, NY.

Shine, J., and L. Dalgarno. 1974. The 3'-terminal sequence of Escherichia coli $16 \mathrm{~S}$ ribosomal RNA: Complementarity to nonsense triplets and ribosome binding sites. Proc. Nat. Acad. Sci. USA. 71:1342-1346.

Tinoco, I. J., P. N. Borer, B. Dengler, M. D. Levine, O. C. Uhlenbeck, and D. M. Crothers. 1973. Improved estimation of secondary structure in ribonucleic acids. Nature (London) New Biol. 246:40-41.

Tsakalidou, E., and G. Kalantzopoulos. 1992. Purification and partial characterization of an esterase from Lactococcus lactis ssp lactis strain ACA-DC 127. Lait 72:533-543.

Urbach, G. 1995. Contribution of lactic acid bacteria to flavour compound formation in dairy products. Int. Dairy J. 5:877-903.

Woo, A. H., S. Kollodge, and R. C. Lindsay. 1984. Quantification of major free fatty acids in several cheese varieties. J. Dairy Sci. $67: 874-878$.

Woo, A. H., and R. C. Lindsay. 1984. Concentrations of major free fatty acids and flavor development in Italian cheese varieties. J. Dairy Sci. 67:960-968 